P. Carew, and L. Stapleton (2005). 'Towards a Privacy Framework for Information Systems Development', in O. Vaselicas, W. Wojtowski \& G. Wojtowski (eds.), Information Systems Development: Advances in Theory, Practice and Education, Kluwer Academic Press/ Plenum

\title{
TOWARDS A PRIVACY FRAMEWORK FOR INFORMATION SYSTEMS DEVELOPMENT
}

\author{
Peter J. Carew and Larry Stapleton*
}

\section{INTRODUCTION}

Privacy issues are an increasing concern in our society (Pedersen, 1999). As information and communications technology (ICT) becomes increasingly pervasive, these concerns are being intensified. Privacy is a fundamental human right (UN, 1948) that continues to be violated by intrusive and unethical applications of technology in society and the workplace (cf. Baase, 2003). However, in spite of the ethical concerns and the pivotal role ICT plays in gathering and processing information on people, privacy remains a misunderstood and undervalued concept in ISD.

Although literature addresses many ethical issues associated with intrusive technologies, privacy has received very little attention from ISD researchers, with mainstream literature treating privacy as analogous to data security. Palen and Dourish (2003) note that social and design studies of technology often unknowingly conflate the many functions of privacy and consequently fail to provide sufficient analytical treatment. Current ISD approaches are failing to recognise the significance of privacy issues that affect those involved in the development and deployment of information systems. Privacy violations result in a plethora of negative side effects (e.g. stress, anxiety, resistance) and these may be contributing to the high failure rate of ISD projects.

Although traditional ISD approaches have long recognised the importance of the social element, they continue to focus upon technical issues (Stapleton, 2001). Most methodologies neglect the social interaction and dynamics inherent in the development and deployment process, creating serious problems for the ISD process. Social interaction is a core aspect of ISD, with many processes requiring interaction between various parties. Requirements elicitation (interviews, observation, retrospection, etc.), prototyping, feedback, walkthroughs and numerous other ISD processes require intensive social interaction between analysts, users and other stakeholders. However, there are numerous privacy ramifications pertinent to such interactions, and these ramifications bear heavily upon the success or failure of ISD. For example, individuals will not freely and openly participate in a process, which not only is itself intrusive (examining their work, lives, characters, skills, etc.) but also results in a system that may negatively affect

${ }^{*}$ ISOL Research Centre, Waterford Institute of Technology, Ireland. 
their jobs. Resistance will result, and can include overt or covert behaviours such as conflict, sabotage, coercion, avoidance and withholding or distorting information (Hirschheim and Newman, 1988). Superficially these behaviours can seem irrational and are often treated as such in the literature (see for example ideas of the irrationality of user resistance to change). However, according to a rationality based upon privacy, these behaviours become very rational. The satisfaction of privacy needs leads to effective individual and group functioning (Pedersen, 1999). By implication, ignoring privacy issues during ISD will create serious problems.

Palen and Dourish (2003) advocate the incorporation of privacy rationalities into systems analysis and design. However, while their central concern is with how privacy is conducted in the presence of technology, this can be taken a step further to include the ISD process itself, and not just the product of that process. Palen and Dourish (2003, p.130) note "fuller treatment of privacy and technology merits a deeper examination of this background [privacy theory]."

This paper expands upon the work of Palen and Dourish, and supplies a fuller treatment of privacy in ISD. It explores the theoretical roots of privacy and a number of related ethical issues posed by technology are highlighted. In particular this paper notes the absence of any coherent framework into which privacy issues relating to ISD are organised. In response to this, a preliminary conceptual framework for interpreting privacy in ISD is presented and subsequently applied to five ISD methodologies in order to provide a reasonably comprehensive assessment of the current state of ISD research in this area.

The next section provides the reader with a brief overview of the key dimensions of privacy as set out in the literature. This provides a basis for the rest of the paper where implications for ISD are set out, and methodologies are assessed.

\section{PRIVACY: A REVIEW OF THE LITERATURE}

The concept of privacy appears in the literature of several disciplines. There is no universal definition for privacy, and numerous authors have highlighted the difficulties in producing such a definition (cf. Burgoon, 1982; Leino-Kilpi, et al., 2001; Newell, 1998). Theorists argue over whether privacy is a condition, a process or a goal (Newell, 1998). While privacy may be a difficult concept to characterise concisely, the various definitions do have substantial commonalities. One group of definitions emphasise seclusion, withdrawal, and avoidance of interaction with others. The second group puts more emphasis on the control individuals have over their lives.

There are a number of formal models of privacy in the literature, but the theories of Alan Westin (e.g. Westin, 1970) and Irwin Altman (e.g. Altman, 1976) are considered authoritative. Their theories and ideas have stood the test of time and have been the basis of research for many subsequent authors (Margulis, 2003; Pedersen, 1999, 1997; Petronio, 1991). The remainder of this section provides an aggregated overview of some of the core aspects of privacy compiled from the most influential literature. These core aspects set out the theoretical background against which any ISD privacy theory must be constructed. 


\subsection{Privacy Types, Functions and Mechanisms}

People experience and desire several states, or types, of privacy. These include the four identified by Westin (1970): solitude, intimacy, anonymity and reserve. Solitude means to be alone and free from observation by others. Intimacy refers to being alone with a small group to the exclusion of others (e.g. family), and concerns close relationships. Anonymity refers to being unrecognised in a public place - to be inconspicuous and blend into the crowd. Reserve is based on a desire to limit disclosures to others. Pedersen $(1997,1999)$ extended Westin's model by adding isolation (i.e. using physical distance to be alone) and splitting intimacy into intimacy with family and intimacy with friends. Burgoon (1982) identified the following broad dimensions of privacy: social, physical, informational and psychological.

Privacy functions refer to why individuals seek privacy. Westin (1970) identified four functions of privacy: personal autonomy, emotional release, self-evaluation, and limited and protected communication. Personal autonomy relates to independence and self-identity. It is the desire to avoid being manipulated, dominated or exposed by others. Emotional release refers to freedom from the tensions of social life, and being able to deviate from social norms, roles, rules and customs safely. Self-evaluation refers to integrating experience into meaningful patterns, and the opportunity to plan and assess future actions (i.e. self-reflection and assessment). Limited and protected communication provides the opportunity to share personal information with trusted others. Altman (1976) describes three functions of privacy: interpersonal, the interface to the self and the social world, and self-identity. Pedersen $(1997,1999)$ empirically identified five basic functions of privacy: contemplation, autonomy, rejuvenation, confiding and creativity. From a systems point of view, Newell (1998) argues that privacy provides an opportunity for restabilisation, system maintenance (i.e. healthy physiological and cognitive functioning) and system development (i.e. towards autonomy and self-actualisation). Individuals may seek to protect their privacy to avoid e.g. embarrassment, harassment, ridicule, shame, scrutiny or discrimination (Shapiro and Baker, 2001).

Behavioural mechanisms are used to achieve a desired level of privacy. These mechanisms include verbal, paraverbal (e.g. tone), non-verbal (e.g. gestures), environmental behaviour (e.g. personal space and territoriality), and cultural norms and customs (Altman, 1976; Pedersen, 1999). Personal space is an invisible zone surrounding the human body, separating people from one another (Leino-Kilpi, et al., 2001). Territoriality refers to a perceived ownership of areas, objects, knowledge or status. These privacy mechanisms function as an integrated system, supporting and substituting each other as appropriate (Altman, 1976).

\subsection{Circumstance, Individuality and Culture}

Privacy interests vary in both content and magnitude across situations and individuals. What may be trivial to one individual may be significant to another (Shapiro and Baker, 2001). Relevant personal factors include the individual's need for privacy, personal attractiveness, interpersonal skills, personality variables, and ability to use privacy control mechanisms effectively (Pedersen, 1999). Personality variables include extraversion, emotional stability, agreeableness, openness to experience, and conscientiousness (Zweig and Webster, 2003). Gender also can impact on privacy preferences (Newell, 1998; Pedersen, 1999). Some cultures have a stronger preference 
for privacy and more privacy needs than others (Kaya and Weber, 2003). The need for privacy is universal but manifestations and privacy mechanisms are culturally specific (Margulis, 2003; Newell, 1998). For example, local culture has been shown to affect people's perceptions of crowding (Hall, 1966).

\subsection{Intrusion and Privacy Violation}

Intrusion essentially is when the desired level for privacy is higher than the actual level being enjoyed (Altman, 1976). Altman's process oriented model for social interaction is useful for further describing what is meant by intrusion or privacy violation. In Altman's theory, privacy has five properties: units of privacy, the dialectic nature of privacy, the non-monotonic nature of privacy, privacy as a boundary control process, and privacy as a bi-directional process (Altman, 1976). Units of privacy refer to the fact that privacy applies at the individual and group levels, and differences exist in privacy dynamics for various social units (Altman, 1976; Margulis, 2003). The units of privacy can be person-to-person, person-to-group, group-to-person or group-to-group (LeinoKilpi, et al., 2001). The dialectic nature of privacy refers to the fact that individuals continuously change their desire for interpersonal contact. There are two opposing forces at work at all times - one drawing individuals together, and another pushing them apart. Privacy can, thus, be viewed as a dynamic, dialectic process where the need for solitude and the need for interpersonal contact are constantly in opposition. The desired level of privacy depends on which of the two opposing forces is strongest at a given time. The non-monotonic nature of privacy refers to the fact that there is an optimal level of privacy at a given time, and people can have too much privacy (e.g. social isolation) or too little privacy (e.g. crowding). Privacy as a boundary regulation process offers the notion of a flexible barrier between the self and non-self, which can be opened or closed depending on circumstance (Altman, 1976; Petronio, 1991). Finally, privacy can be viewed as a bidirectional process, involving controlling inputs from others and outputs to others.

In terms of Altman's model, intrusion therefore depends on a number of factors. Different social units have different privacy needs (e.g. family, work group, individual), these needs change frequently, and it is possible to have too much or too little privacy. While too much interaction may be experienced as an invasion of privacy, too little may be experienced as loneliness or alienation (Pedersen, 1999). Being forced to interact (i.e. receive input or provide output) beyond the level of interaction desired in a given circumstance is an intrusion as the forced participation implies an attempt to break through the flexible mental barrier (cf. Altman, 1976). The ability to control interactions is essential for privacy management.

Technology has long been recognised as posing a significant threat to the privacy of personal data. The following section looks at some of the privacy related ethical issues in the information society. It shows how ICT is shaping society and the workplace and highlights some dilemmas facing the ethical ISD professional.

\section{TECHNOLOGY, PRIVACY VIOLATION AND ETHICAL ISSUES}

The human-centred and soft-systems traditions of ISD have an underlying belief that new technologies should be for the benefit of all people and all societies (Gill, 1996; Checkland, 1999). Technology design should, therefore, be concerned not only with 
technical feasibility (i.e. can we do it?) but also with a social desirability (i.e. do we want to do it?). Privacy is one human factor that must be considered in this context.

Privacy concerns are being fuelled by increasingly intrusive and pervasive technologies in society and the workplace. For example, employers can monitor employees' email, web usage, keystrokes, telephones, transactions, computer screens and location. Monitored employees experience a myriad of negative effects including stress, low morale, anxiety, depression, decreased job satisfaction, lack of involvement, paced work, health problems, lack of control, fear over job loss and a decline in work relationships (Oz, et al., 1999; Ariss, 2002). In addition monitored workers are likely to have higher turnovers, take additional sick days, and work to rule. Furthermore, employees do not passively accept surveillance technologies and may attempt to resist and distort information gathering. Numerous analysts argue that many privacy intrusions are immoral, unnecessary, excessive and self-indulgent voyeurism (cf. Stone and StoneRomero, 1998).

For many organisations, human-centred issues like privacy are not compatible with organisational life where a competitive, lean rationality and shareholder value are emphasised (Gill, 1996; Brandt and Cernetic, 1998). However, economic calculations frequently fail to place sufficient value on social issues, human capital and the environment. Organisations do have obligations to their stakeholders and shareholders, but they also have ethical responsibilities for protecting the privacy, welfare and dignity of their employees (Stone and Stone-Romero, 1998). Privacy is a fundamental human right, recognised by the United Nations (UN, 1948). Treating it as anything but a human right is globally established as unethical behaviour. A balance should therefore be sought between an employer's legitimate business interests and the employee's legitimate privacy concerns (Ariss, 2002). This includes the ISD process.

The following section presents a developmental framework for analysing privacy dynamics in ISD. This provides a basis for assessing individual and group privacy needs and factors in the context of information systems development and deployment within organisations.

\section{A CONCEPTUAL FRAMEWORK FOR PRIVACY IN ISD}

This section presents a framework for evaluating and interpreting privacy issues in ISD. The framework includes various privacy factors from the literature that may affect an ISD project. Some factors have been renamed or slighted redefined to correspond more closely to an ISD context (e.g. organisational focus as opposed to a public focus). The framework is structured into four dimensions containing related privacy factors. Table 1 provides a brief overview of all factors in the framework.

The four dimensions have been taken from Burgoon (1982): physical, social, psychological and informational. The physical dimension refers to the environment (e.g. workspace, office, etc.) where an individual may seek physical solitude. Social privacy refers to the freedom to withdraw from, or enter into, interactions with others. Psychological privacy is closely related to the social dimension, but refers only to the individual psyche. Finally, informational privacy refers to an individual's ability to control personal information. These dimensions are not unambiguously discrete, and there is some overlap between them. However, they provide welcome structure for classifying the myriad of privacy factors found in the literature. Each factor has been 
classified as being: a privacy type $(\mathrm{T})$, a privacy function $(\mathrm{F})$ or a contributing privacy factor (C). Some contributing factors have been identified as (mainly) local to one of the four dimensions whereas others have global significance, affecting all aspects of privacy. The reader should also note how the table anchors each aspect of privacy in the privacy literature, providing details of the sources of each aspect.

Figure 1 provides a graphical representation of the framework. Working from the centre out, the figure shows: the higher order psychological functions of privacy; the four main dimensions of privacy; the types of privacy experienced or desired for each dimension; factors contributing to privacy for each dimension (local); and the outer concentric rings show the global contributing privacy factors. In order to ascertain the levels to which current ISD methodologies consider privacy the following section applies the framework to a selection of ISD methodologies.

Table 1. Overview of Privacy Framework Factors

\begin{tabular}{|c|c|c|c|}
\hline & Aspect & $\mathbf{C}$ & Description \\
\hline \multirow{8}{*}{ 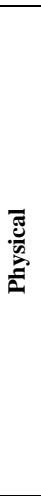 } & Environment & $\mathrm{T}$ & $\begin{array}{l}\text { Individual's physical environment e.g. workplace. Personal space. Crowding may violate. } \\
\text { [Refs: Burgoon (1982); Hall (1966); Margulis (2003)] }\end{array}$ \\
\hline & $\begin{array}{l}\text { Territoriality } \\
\text { (Property) }\end{array}$ & $\mathrm{T}$ & $\begin{array}{l}\text { Property owned, or perceived to be owned, by an individual. Examples: home, office, } \\
\text { equipment, information system, network, etc. [Refs: Burgoon (1982); Altman (1976)] }\end{array}$ \\
\hline & $\begin{array}{l}\text { Territoriality } \\
\text { (Body) }\end{array}$ & $\mathrm{T}$ & $\begin{array}{l}\text { A person's body. The most inviolate of territories. Unwelcome contact (tactile, visual, etc.) } \\
\text { is a violation. [Refs: Burgoon (1982)] }\end{array}$ \\
\hline & $\begin{array}{l}\text { Solitude } \\
\text { (Physical) }\end{array}$ & $\mathrm{T}$ & $\begin{array}{l}\text { Free from direct or remote observation or surveillance. Sanctuary. Seclusion. [Refs: } \\
\text { Burgoon (1982); Pedersen }(1997,1999) ; \text { Westin }(1970)]\end{array}$ \\
\hline & Repose & $\mathrm{T}$ & Freedom from anything that disturbs or excites. [Refs: Burgoon (1982)] \\
\hline & Physical Access & $\mathrm{C}$ & The ability to physically control access to the self. [Refs: Altman (1976); Burgoon (1982)] \\
\hline & $\begin{array}{l}\text { Sensory and } \\
\text { Communication } \\
\text { Channels }\end{array}$ & $\mathrm{C}$ & $\begin{array}{l}\text { The greater the number of channels of communication (or senses) the less privacy enjoyed. } \\
\text { Communications technologies such as email, mobile phones, etc. can also be considered. } \\
\text { [Refs: Burgoon (1982)] }\end{array}$ \\
\hline & $\begin{array}{l}\text { Violator } \\
\text { (Humanness and } \\
\text { Relationship) }\end{array}$ & $\mathrm{C}$ & $\begin{array}{l}\text { The degree of violation depends on the relationship towards the violator. Non-humans (e.g. } \\
\text { machines, animals) are not as invasive as humans. Family, friends and those held in low } \\
\text { esteem are the least intrusive. Respected humans/acquaintances are the most intrusive. [Refs: } \\
\text { Burgoon (1982)] }\end{array}$ \\
\hline \multirow{10}{*}{ 焉 } & $\begin{array}{l}\text { Intimacy } \\
\text { (External) }\end{array}$ & $\mathrm{T}$ & $\begin{array}{l}\text { Intimacy with family, friends, etc. external to the organisation. Intimacy requires the } \\
\text { exclusion of others to a group. [Refs: Pedersen }(1997,1999) \text {; Westin }(1970)]\end{array}$ \\
\hline & $\begin{array}{l}\text { Intimacy } \\
\text { (Internal) }\end{array}$ & $\mathrm{T}$ & $\begin{array}{l}\text { Intimacy with colleagues, peers, managers, etc. within the organisation. Intimacy requires the } \\
\text { exclusion of others to a group. [Refs: Pedersen }(1997,1999) \text {; Westin }(1970)]\end{array}$ \\
\hline & $\begin{array}{l}\text { Territoriality } \\
\text { (Status) }\end{array}$ & $\mathrm{T}$ & $\begin{array}{l}\text { Social status or prestige held (or perceived to be held) within the organisation. Dignity. } \\
\text { Respect of others. [Refs: Leino-Kilpi et al. (2001)] }\end{array}$ \\
\hline & Solitude (Social) & $\mathrm{T}$ & $\begin{array}{l}\text { Individual freedom from interactions with others. Sanctuary. [Refs: Burgoon (1982); } \\
\text { Pedersen (1997, 1999); Westin (1970)] }\end{array}$ \\
\hline & Anonymity & $\mathrm{T}$ & $\begin{array}{l}\text { Not being personally identified/known. To go unnoticed. Blend into the crowd. Freedom } \\
\text { from being singled out. [Refs: Pedersen }(1997,1999) ; \text { Westin (1970)] }\end{array}$ \\
\hline & Autonomy & $\mathrm{T}$ & $\begin{array}{l}\text { Freedom to make own decisions. Protection from interference or coercion by others. Group } \\
\text { or individual. [Refs: Pedersen (1997, 1999); Westin (1970); Margulis (2003); Burgoon } \\
(1982) \text { ] }\end{array}$ \\
\hline & $\begin{array}{l}\text { Interactions \& } \\
\text { Communication }\end{array}$ & $\mathrm{C}$ & $\begin{array}{l}\text { Control over who to interact with, how frequent these interactions are, how long these } \\
\text { interactions are, and the contents/topics of the interactions. [Refs: Altman (1976); Burgoon } \\
\text { (1982); Petronio (1991)] }\end{array}$ \\
\hline & Formality & $\mathrm{C}$ & The degree of formality of the interactions. [Refs: Burgoon (1982)] \\
\hline & Units & $\mathrm{C}$ & $\begin{array}{l}\text { Privacy needs exist amongst various social units e.g. individual, group, individual-individual } \\
\text { (dyadic), individual-group, group-group, etc. [Refs: Altman (1976); Burgoon (1982); Leino- } \\
\text { Kilpi et al. (2001)] }\end{array}$ \\
\hline & $\begin{array}{l}\text { Personalness of } \\
\text { Topic }\end{array}$ & $\mathrm{C}$ & $\begin{array}{l}\text { The more personal the content/topic of an interaction, the higher the probability of a privacy } \\
\text { violation. [Refs: Burgoon (1982)] }\end{array}$ \\
\hline
\end{tabular}


Table 1. (Continued).

\begin{tabular}{|c|c|c|c|}
\hline & Aspect & $\mathbf{C}$ & Description \\
\hline \multirow{9}{*}{ 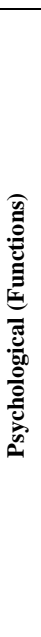 } & Self-Identity & $\mathrm{F}$ & $\begin{array}{l}\text { Development of self-identify/self-ego. Towards self-actualisation. [Refs: Altman (1976); } \\
\text { Newell (1998); Westin (1970); Burgoon (1982)] }\end{array}$ \\
\hline & Personal Growth & $\mathrm{F}$ & $\begin{array}{l}\text { Intellectual, emotional and spiritual growth. [Refs: Altman (1976); Burgoon (1982); } \\
\text { Newell (1998)] }\end{array}$ \\
\hline & Autonomy & $\mathrm{F}$ & $\begin{array}{l}\text { Freedom to make own decisions. Protection from interference or coercion by others. } \\
\text { Independence. [Refs: Pedersen (1997, 1999); Westin (1970); Margulis (2003); Burgoon } \\
(1982) \text { ] }\end{array}$ \\
\hline & Contemplation & $\mathrm{F}$ & $\begin{array}{l}\text { Self-evaluation and reflection. Learning from and interpreting recent experiences. } \\
\text { Planning for future based on experiences. [Refs: Westin (1970); Pedersen }(1997,1999) \text {; } \\
\text { Altman (1976); Burgoon (1982)] }\end{array}$ \\
\hline & Self-Protection & $\mathrm{F}$ & $\begin{array}{l}\text { Being able to conceal sensitive or potentially harmful information. Security. Diverge from } \\
\text { norms/experiment without penalty. [Refs: Burgoon (1982); Shapiro and Baker (2001)] }\end{array}$ \\
\hline & Confiding & $\mathrm{F}$ & $\begin{array}{l}\text { Disclosing information to others in a secure fashion (i.e. to the exclusion of others). } \\
\text { Limited and protected communication. [Refs: Pedersen (1997, 1999); Westin (1970); } \\
\text { Altman (1976)] }\end{array}$ \\
\hline & Emotional Release & $\mathrm{F}$ & $\begin{array}{l}\text { Relax from social roles and deviate from norms and customs in a protected fashion. Such } \\
\text { backstage behaviour allows individuals to escape from conformity and to experiment } \\
\text { outside those norms safely. [Refs: Burgoon (1982); Westin (1970)] }\end{array}$ \\
\hline & Rejuvenation & $\mathrm{F}$ & $\begin{array}{l}\text { Recover from life in general (fatigue, stress, etc.) and assaults on self-esteem. } \\
\text { Restabilisation. System maintenance. Group or individual. [Refs: Burgoon (1982); Newell } \\
\text { (1998); Pedersen }(1997,1999)]\end{array}$ \\
\hline & Creativity & $\mathrm{F}$ & Freedom to be creative, innovate, etc. [Refs: Burgoon $(1982) ;$ Pedersen $(1997,1999)]$ \\
\hline \multirow{5}{*}{ 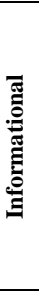 } & $\begin{array}{l}\text { Territoriality } \\
\text { (Knowledge) }\end{array}$ & $\mathrm{T}$ & $\begin{array}{l}\text { Any action that makes an individual's knowledge/skills less valuable (e.g. codifying, } \\
\text { rendering redundant, etc.) may be considered a violation. [Refs: Leino-Kilpi et al. (2001)] }\end{array}$ \\
\hline & Reserve & $\mathrm{T}$ & $\begin{array}{l}\text { Limit knowledge of the self to others. Violations would include any action that exposes } \\
\text { sensitive personal information. [Refs: Pedersen }(1997,1999) ; \text { Westin }(1970)]\end{array}$ \\
\hline & $\begin{array}{l}\text { Release of } \\
\text { Personal Info }\end{array}$ & $\mathrm{C}$ & $\begin{array}{l}\text { The extent to which an individual can control the content and amount of personal } \\
\text { information being released. [Refs: Burgoon (1982)] }\end{array}$ \\
\hline & $\begin{array}{l}\text { Distribution of } \\
\text { Personal Info }\end{array}$ & $\mathrm{C}$ & $\begin{array}{l}\text { The extent to which an individual can control to whom the personal information is being } \\
\text { disclosed (individuals, groups, etc.). [Refs: Burgoon (1982)] }\end{array}$ \\
\hline & $\begin{array}{l}\text { Use of Personal } \\
\text { Info }\end{array}$ & $\mathrm{C}$ & $\begin{array}{l}\text { The extent to which an individual can control the use of the released personal information } \\
\text { (e.g. performance monitoring, direct marketing, etc.). [Refs: Burgoon (1982)] }\end{array}$ \\
\hline \multirow{5}{*}{$\frac{\bar{\sigma}}{\frac{\pi}{0}}$} & Control & $\mathrm{C}$ & $\begin{array}{l}\text { Ability and freedom to alter social interactions and situations. [Refs: Altman (1976); } \\
\text { Petronio (1991)] }\end{array}$ \\
\hline & $\begin{array}{l}\text { Personal } \\
\text { Characteristics \& } \\
\text { Circumstance } \\
\end{array}$ & $\mathrm{C}$ & $\begin{array}{l}\text { An individual's personality and other personal traits have a bearing on their need for } \\
\text { privacy. Privacy is circumstantial, changing with time and situation. [Refs: Pedersen } \\
\text { (1999); Shapiro and Baker (2001); Zweig and Webster (2003)] }\end{array}$ \\
\hline & Organisational & $\mathrm{C}$ & $\begin{array}{l}\text { Organisational culture, factors, management style, stakeholders, etc. affect privacy. [Refs: } \\
\text { Stone and Stone-Romero (1998)] }\end{array}$ \\
\hline & Cultural & $\mathrm{C}$ & $\begin{array}{l}\text { Culture affects privacy. Privacy is a universal need, but manifests in different ways in } \\
\text { different cultures and societies. [Refs: Hall (1966); Kaya and Weber (2003); Altman } \\
\text { (1976); Newell (1998)] }\end{array}$ \\
\hline & Societal & $\mathrm{C}$ & $\begin{array}{l}\text { Society (local and global) has a bearing on privacy. [Refs: Hall (1966); Kaya and Weber } \\
\text { (2003); Newell (1998); Shapiro and Baker (2001)] }\end{array}$ \\
\hline
\end{tabular}

\section{APPLYING THE FRAMEWORK TO FIVE ISD METHODOLOGIES}

In this section, the conceptual privacy framework is applied to the following methodologies: UML/UP (OO), SSADM (structured), SSM (soft), Multiview (contingency) and ETHICS (participatory, socio-technical). The methodologies were chosen so as to provide ample coverage of both hard and soft approaches to ISD.

\subsection{Method}

Jacobson et al. (1999) was chosen as representative for UML/UP. For the remaining methodologies, Avison and Fitzgerald (1995) provide comprehensive overviews. These 


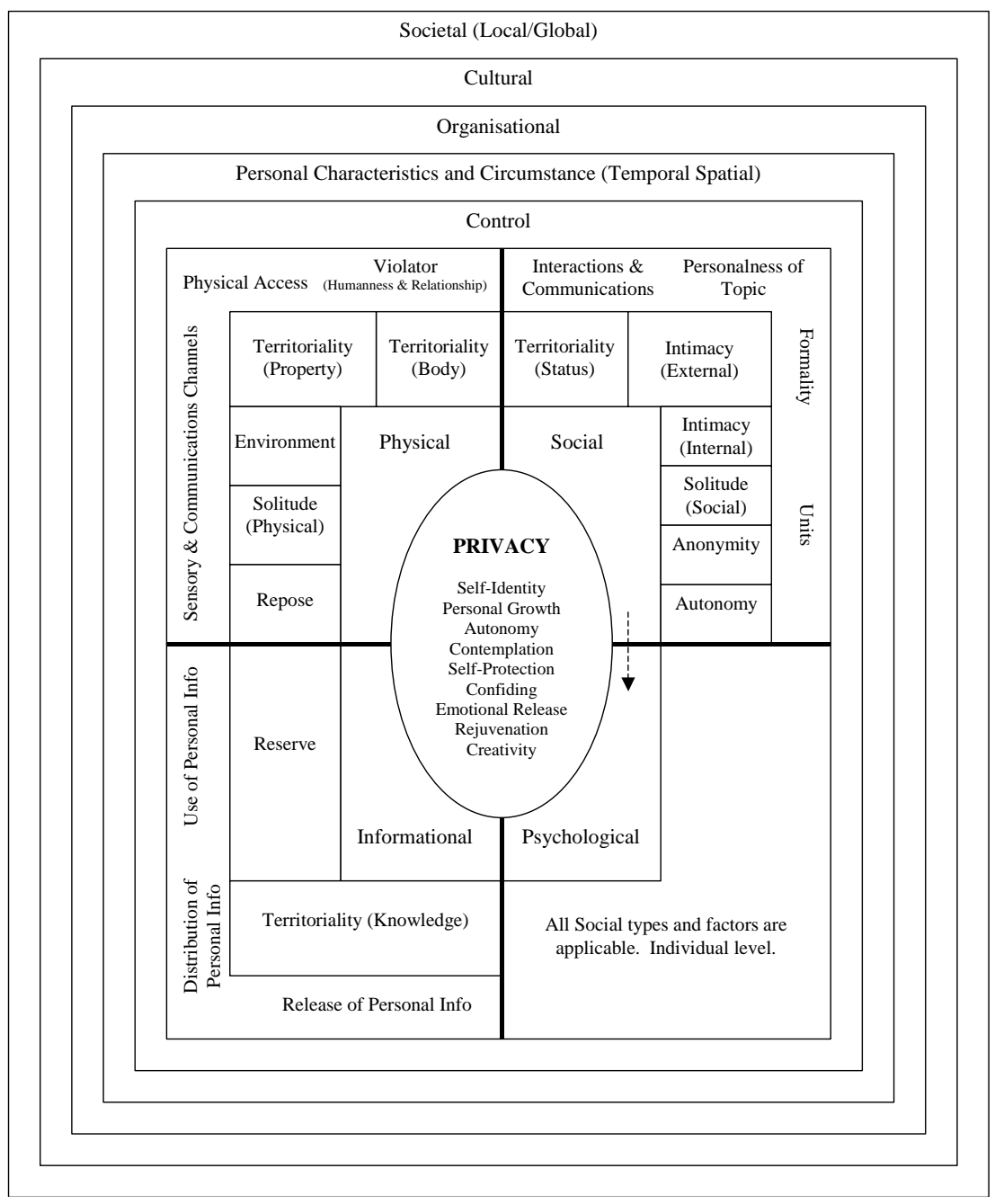

Figure 1. A Privacy Framework for Information Systems Development

overviews were supported by one additional authoritative source each: Weaver (1993) for SSADM, Checkland and Scholes (1990) for SSM, Avison and Wood-Harper (1990) for Multiview, and Mumford (2000) for ETHICS. The study focussed on the main stages of the methodologies, with particular attention to the human-oriented processes. While analysing the methodologies, any stage or description that potentially support or neglect particular privacy factors (types, functions, contributors) in the framework were noted. Note that it is possible for a section to potentially support and neglect a particular privacy factor, depending on how the process described is interpreted or undertaken. As the methodologies are not primarily concerned with privacy, even superficial references to similar or related concepts were noted. The results of the study are summarised in Table 2. 
Table 2. Results of Privacy Analysis

\begin{tabular}{|c|c|c|c|c|c|c|c|}
\hline Dimension & Aspect & Class & $\begin{array}{c}\text { UML / } \\
\text { UP }\end{array}$ & SSADM & SSM & Multiview & ETHICS \\
\hline \multirow[t]{8}{*}{ Physical } & Environment & $\mathrm{T}$ & - & $++/-$ & + & ++ & + \\
\hline & \begin{tabular}{|l} 
Territoriality (Property) \\
\end{tabular} & $\mathrm{T}$ & + & -- & ++ & + & ++ \\
\hline & Territoriality (Body) & $\mathrm{T}$ & & & & & \\
\hline & \begin{tabular}{|l} 
Solitude (Physical) \\
\end{tabular} & $\mathrm{T}$ & & --- & & & \\
\hline & Repose & $\mathrm{T}$ & & & & & \\
\hline & Physical Access & $\mathrm{C}$ & & $+/--$ & & & \\
\hline & Sensory and Communication Channels & $\mathrm{C}$ & & - & & & \\
\hline & Violator (Humanness and Relationship) & C & & + & & & \\
\hline \multirow[t]{10}{*}{ Social } & Intimacy (External) & $\mathrm{T}$ & & & & & \\
\hline & Intimacy (Internal) & $\mathrm{T}$ & $++/-$ & $+++/--$ & $++1-$ & $++/-$ & + \\
\hline & Territoriality (Status) & $\mathrm{T}$ & & ++ & ++ & +++ & +++ \\
\hline & Solitude (Social) & $\mathrm{T}$ & & $+1--$ & & & \\
\hline & Anonymity & $\mathrm{T}$ & - & --- & & & \\
\hline & \begin{tabular}{|l} 
Autonomy \\
\end{tabular} & $\mathrm{T}$ & & $+/--$ & & ++ & +++ \\
\hline & Interactions and Communications & C & - & $+1---$ & & + & + \\
\hline & Units & $\mathrm{C}$ & & & & + & ++ \\
\hline & Formality & $\mathrm{C}$ & $+/-$ & $++/-$ & & & \\
\hline & Personalness of Topic & $\mathrm{C}$ & & + & & & \\
\hline \multirow{9}{*}{$\begin{array}{l}\text { Psychological } \\
\text { (Functions) }\end{array}$} & Self-Identity & $\mathrm{F}$ & & & & + & ++ \\
\hline & Personal Growth & $\mathrm{F}$ & + & & & + & ++ \\
\hline & \begin{tabular}{|l|l} 
Autonomy \\
\end{tabular} & $\mathrm{F}$ & & -- & & +++ & ++ \\
\hline & Contemplation & $\mathrm{F}$ & & & & & + \\
\hline & Self-Protection & $\mathrm{F}$ & & - & & + & \\
\hline & \begin{tabular}{|l|} 
Confiding \\
\end{tabular} & $\mathrm{F}$ & & & & & \\
\hline & Emotional Release & $\mathrm{F}$ & & & & & \\
\hline & Rejuvenation & $\mathrm{F}$ & & & & & \\
\hline & Creativity & $\mathrm{F}$ & + & + & & + & + \\
\hline \multirow[t]{5}{*}{ Informational } & Territoriality (Knowledge) & $\mathrm{T}$ & + & -- & ++ & & ++ \\
\hline & Reserve & $\mathrm{T}$ & & $+/--$ & + & & \\
\hline & Release of Personal Information & $\mathrm{C}$ & & --- & & - & \\
\hline & \begin{tabular}{|l|} 
Distribution of Personal Information \\
\end{tabular} & $\mathrm{C}$ & & --- & & $+/-$ & \\
\hline & Use of Personal Information & $\mathrm{C}$ & & --- & & - & \\
\hline \multirow[t]{5}{*}{ Global } & Control & C & - & $+/--$ & & +++ & +++ \\
\hline & Personal Characteristics and Circumstance & $\mathrm{C}$ & & & + & + & ++ \\
\hline & Organisational & $\mathrm{C}$ & + & +++ & +++ & ++ & ++ \\
\hline & Cultural & $\mathrm{C}$ & & & +++ & & \\
\hline & Societal & $\mathrm{C}$ & & & ++ & & + \\
\hline
\end{tabular}

Positive Orientation: ++++ (Very Strong), +++ (Strong), ++ (Some), + (Weak)

Negative Orientation: ---- (Very Strong), --- (Strong), -- (Some), - (Weak)

\subsection{Results}

The Unified Modeling Language (UML) is a graphical modelling language for specifying systems from an object-oriented perspective. It is important to recognise that the UML itself is not a methodology, but simply a modelling notation that provides a variety of modelling diagrams but does prescribe underlying processes for developers to follow. However, the authors of UML have offered the Unified Software Development Process (or simply Unified Process) as a suitable methodology (cf. Jacobson, et al., 1999). As UML is oriented towards specifying technical functionality, it does not consider any issues pertinent to people or privacy. Therefore, the Unified Process (UP) is considered in its stead. In terms of the framework, UML/UP performs poorly, paying no discernable attention to privacy issues. The Unified Process is still technically oriented, 
and does not consider the social aspects of ISD in any depth. For example, Jacobson et al. (1999, p.97) state that "management is responsible for non-technical risks." So, according to UML/UP, developers have no responsibility for anything non-technical in the ISD process. Does this, for example, preclude them from considering the ethical ramifications of the systems they are developing or, indeed, how they develop them? This viewpoint is deeply disturbing, especially when presented by a popular, and widely taught, contemporary approach to ISD.

SSADM provides developers with detailed rules, activities, deliverables and guidance for all stages of the project lifecycle. In terms of the privacy framework, SSADM only appears to pay adequate attention to the organisational factors that appear in the global dimension. Many other aspects appear to go against privacy, with users being unable to control access, interactions, anonymity or personal information.

Soft Systems Methodology (SSM) is 7-stage/4-acitvities systems thinking approach to handling real world, unstructured problems. It was originally organised into a seven stage model and later developed into the four activities model (Checkland, 1999). In either case the basic premises and approaches were much the same, focussing as they do upon 'soft' aspects of ISD. Under the privacy framework, SSM did not fare overly well, but this may be partly due to its high-level description. It does address territoriality (conflicts, etc.) to some extent, but its privacy related strengths seem to be in recognising organisational, cultural and societal issues. Given Checkland's deep concern with environmental issues it is not entirely surprising to find that the global dimension of the privacy framework receives most attention in SSM (Checkland, 1999).

Multiview is a 5-stage contingency approach that advocates flexibility in choice of methodology and approach to suit heterogeneous situations. It considers both the human and technical aspects, and is inherently non-prescriptive. Under the privacy framework Multiview performs relatively well, but many factors are not considered. The approach recognises: autonomy, control, territoriality, organisational, and environmental aspects (to varying degrees). Unlike the other methodologies, privacy is addressed explicitly but only in terms of data access and security.

ETHICS is a 6-stage methodology based on the participatory approach to information systems development. It takes a socio-technical view that successful technology should fit closely with social and organisational factors. ETHICS performs respectably under the framework, but many privacy factors are not addressed. The methodology recognises: autonomy, control, territoriality, personal characteristics, organisational factors and the need for individual growth and development.

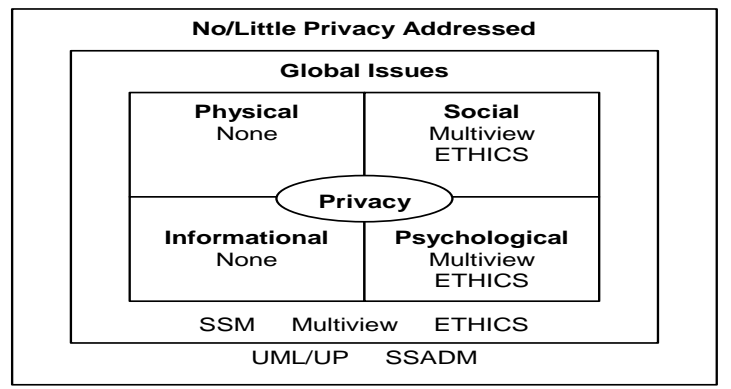

Figure 2. Summarised Assessment of Methodologies Under the Privacy Framework 
Figure 2 shows a high-level classification of the five methodologies based on the privacy framework. No methodology appears to consider physical or informational privacy sufficiently (note that data security alone does not sufficiently address informational privacy). This is significant as technology is a major driver of many privacy violations e.g. surveillance systems that gather vast amounts of personal information and remove opportunities for going unnoticed. It is apparent that privacy is a complex, deeply sensitive human-centric issue that has largely been overlooked by ISD methodologies.

\section{LIMITATIONS OF STUDY}

There are a number of limitations to the critique of the methodologies presented. None of the methodologies reviewed is primarily concerned with the complex notion of privacy as embodied by the framework. Also, with the exception of SSADM, none of the methodologies are overly prescriptive, allowing for some degree of flexibility. Therefore, although the methodologies don't explicitly include or consider privacy, they do not fundamentally preclude it either. Nevertheless, the fact that privacy is not mentioned or addressed at all (except by Multiview in terms of data security) is of some concern. The results presented in Table 2 are also necessarily subjective and compiled from different texts. However, subjective feature-based analyses do exist in the literature (cf. Galliers, 1992; Avison and Fitzgerald, 1995, p.465). Also, comment was passed only on factors that showed reasonably strong orientation in the analysis results. Finally, it is readily apparent that the privacy framework presented here is still in a developmental state. In spite of these limitations it is reasonable to say that none of the reviewed methodologies address privacy sufficiently.

\section{DISCUSSION AND CONCLUSIONS}

Privacy is often misunderstood to be synonymous with secrecy and data security. However, privacy is mainly a social control process that serves a myriad of higher-order social and developmental functions. Organisations should try to balance their need for information against employees' expectations of privacy (Stone and Stone-Romero, 1998). Through doing so, they can realise numerous indirect benefits in terms of ICT (e.g. reduced user resistance and ISD failure) and human capital (e.g. improved creativity).

It is apparent that little is known of privacy dynamics in ICT and especially ISD. The future direction of this research involves a field study using an instrument based on a revised form of the framework presented in this paper. The ultimate goal of this work is to develop a set of privacy-based rationalities for improving the ISD process, making it both more successful and humanitarian. In the meantime, ISD professionals and researchers can use the preliminary framework presented here to assess appropriate methods and practices as regards their privacy orientation.

In conclusion, this paper has highlighted the importance of privacy in the context of ISD. Privacy theory was briefly reviewed and a provisional conceptual framework for interpreting privacy in ISD presented and applied to five ISD methodologies. The results indicate that privacy is not being considered as an important socio-technical factor in 
ISD, and the serious ramifications of this were highlighted. The ongoing research aims to redress this major gap in the ISD literature.

\section{REFERENCES}

Altman, I., 1976, Privacy: A conceptual analysis. Environment and Behavior, 8(1), 7-29.

Ariss, S.S., 2002, Computer monitoring: benefits and pitfalls facing management. Information \& Management, 39(7), 553-558

Avison, D.E. and Fitzgerald, G., 1995, Information Systems Development: Methodologies, Techniques and Tools, Second Edition., McGraw-Hill, London.

Avison, D.E. and Wood-Harper, A.T., 1990, Multiview : An Exploration of Information Systems Development, Blackwell, Oxford

Baase, S., 2003, A Gift of Fire: Social, Legal and Ethical Issues for Computers and the Internet, Second Edition, Prentice Hall, NJ.

Brandt, D. and Cernetic, J., 1998, Human-centred approaches to control and information technology: European experiences, AI \& Society, 12, 2-20.

Burgoon, J., 1982, Privacy and communication, in: Comms Yearbook 6, M. Burgoon, ed., Sage, CA, pp.206-249

Checkland, P. and Scholes, J., 1990, Soft Systems Methodology in Action, Wiley, Chichester.

Checkland, P., 1999, Soft Systems Methodology: A 30-Year Retrospective, Wiley, Chichester.

Galliers, R.D., 1992, Choosing information systems research approaches, in: Information Systems Research, R. Galliers, ed., Blackwell, Oxford, pp.144-162

Gill, K.S., 1996, The human-centred movement: the British context, AI \& Society, 1996(10), 109-126.

Hall, E.T., 1966, The Hidden Dimension, Doubleday, New York.

Hirschheim, R. and Newman, M., 1988, Information systems and user resistance: theory and practice, The Computer Journal, 31(5), 398-408

Hirschheim, R. and Newman, M., 1991, Symbolism and information systems development: myth, metaphor and magic, Information Systems Research, 2(1), 29-62.

Jacobson, I., Booch, G. and Rumbaugh, J., 1999, The Unified Software Development Process, Addison-Wesley, MA.

Kaya, N. and Weber, M.J., 2003, Cross-cultural differences in the perception of crowding and privacy regulation: American and Turkish students, Journal of Environmental Psychology, 23(3), 301-309.

Leino-Kilpi, H., Valimaki, M., Dassen, T., Gasull, M., Lemonidou, C., Scott, A. and Arndt, A., 2001, Privacy: a review of the literature, International Journal of Nursing Studies, 38(6), 663-671.

Margulis, S.T., 2003, On the status and contribution of Westin's and Altman's theories of privacy, Journal of Social Issues, 59(2), 411-429.

Mumford, E., 2000, A socio-technical approach to systems design, Requirements Engineering, 5, 125-133.

Newell, P.B., 1998, A cross-cultural comparison of privacy definitions and functions: a systems approach, Journal of Environmental Psychology, 18(4), 357-371.

Oz, E., Glass, R. and Behling, R., 1999, Electronic workplace monitoring: What employees think, Omega, 27(2), 167-177.

Palen, L. and Dourish, P., 2003, Unpacking "privacy" for a networked world, Proceedings of the conference on Human factors in computing systems, Ft. Lauderdale, Florida, 129-136

Pedersen, D.M., 1997, Psychological functions of privacy. Journal of Environmental Psych., 17(2), 147-156.

Pedersen, D.M., 1999, Model for types of privacy by privacy functions, Journ. of Envir. Psych., 19(4), 397-405.

Petronio, S., 1991, Communication boundary management: a theoretical model of managing discourse of private information between marital couples, Communication Theory, 1(4), 311-335.

Shapiro, B. and Baker, C.R., 2001, Information technology and the social construction of information privacy, Journal of Accounting and Public Policy, 20(4-5), 295-322.

Stapleton, L., 2001, Information Systems Development: An Empirical Study of Irish Manufacturing Firms, Ph.D Thesis, University College Cork.

Stone, D.L. and Stone-Romero, E.F., 1998, A multiple stakeholder model of privacy in organizations, in: Managerial Ethics: Moral Mgmt. of People and Processes, M. Schminke, ed., Erlbaum, NJ, pp.35-39.

UN, 1948, United Nations Universal Declaration of Human Rights, http://www.un.org/Overview/rights.html

Weaver, P.L., 1993, Practical SSADM Version 4, Pitman, London.

Westin, A., 1970, Privacy and Freedom, Atheneum, New York.

Zweig, D and Webster, J., 2003, Personality as a moderator of monitoring acceptance, Computers in Human Behavior, 19(4), 479-493. 